\title{
Seroprevalence of cytomegalovirus and rubella among pregnant women in western Sudan
}

\author{
Hamdan Z Hamdan ${ }^{1}$, Ismail E Abdelbagi ${ }^{2}$, Nasser M Nasser ${ }^{2}$ and Ishag Adam²*
}

\begin{abstract}
Background: Maternal cytomegalovirus (CMV) and rubella infections have adverse neonatal outcomes. Basic epidemiological data concerning CMV and rubella is necessary for health planners and care providers.

Methods: A cross sectional study was conducted at El-Rahad hospital, Sudan to investigate seroprevalence of CMV and rubella infections and associated possible risk factors among pregnant women. Structured questionnaires were used to gather socio-demographic data and ELISA was used to detect CMV and rubella infections using IgG and $\lg \mathrm{M}$.

Results: Out of 231 pregnant women, 167 (72.2\%) and 151 (65.3\%) were CMV-lgG and rubella-lgG positive, respectively. Only $6(2.5 \%)$ and 8 women (3.4\%) were CMV-IgM and rubella-IgM positive, respectively. While, high parity $(\mathrm{OR}=14.7,95 \% \mathrm{Cl}=1.7-123.6 ; P=0.01]$ and illiteracy $(\mathrm{OR}=3.0, \mathrm{Cl}=1.4-6.5 ; P=0.004)$ were significantly associated with seropostive CMV-lgG in multivariate analysis, none of the other obstetrical and medical characteristics were significantly associated with CMV or rubella infections.

Conclusion: CMV prevalence was $72.2 \%$ and rubella susceptibility among pregnant women was $34.6 \%$. Rubella vaccine and routine screening for rubella and CMV should be introduced for pregnant women in this setting. Further research is needed.
\end{abstract}

\section{Introduction}

Maternal Cytomegalovirus (CMV) is the commonest viral infection in perinatal period and it is the leading cause for congenital CMV infection with a permanent hearing, vision loss and neurological impairment [1-3]. It have been reported that, Africa continent have one of the highest prevalence of CMV e.g. in neighboring Egypt, CMV seroprevalence among pregnant women was $96 \%[3,4]$. Maternal sexual behavior and contact with infected young children were the known source of infection [5]. While CMV has asymptomatic infection, rubella infection is mild or self limiting disease, transmitted through respiratory system and to growing fetus through placenta [6,7]. Maternal infection especially during the first trimester associated with adverse neonatal outcome which encompass heart disease, cataract and deafness collectively known as congenital rubella syndrome which had a major neonatal morbidity and burden to families [8]. Although, incidence of rubella

\footnotetext{
* Correspondence: ishagadam@hotmail.com

${ }^{2}$ Faculty of Medicine, University of Khartoum, Khartoum, Sudan

Full list of author information is available at the end of the article
}

infection is reduced worldwide, some African countries like Mozambique still has a high incidence (95.3\%) $[9,10]$. Rubella vaccine is cost-effective and cost-beneficial, therefore since year 2000 WHO proposed an introduction of rubella vaccine program in each country [11].

There is no published data concerning CMV and rubella seroprevalence in pregnant women in Sudan. The basic data concerning CMV and rubella infections during pregnancy is important for health planners and care providers. Thus, this was the aim of the current study as to investigate seroprevalence, associated possible risk factors for CMV and rubella infections among pregnant women in west Sudan. This work is the part of collaborative projects between University of Khartoum and Ministry of Health Sudan so as to provide the later with basic data necessary for intervention [12].

\section{Methods}

This was a cross-sectional study conducted at Antenatal Care Clinic of El-Rahad hospital, western Sudan during the period of August - October 2009. Consecutive pregnant women were approached to participate in the

\section{Biomed Central}


study. After signing an informed consent, relevant medical, obstetrical, socio-demographic characteristics were gathered using pre-tested questionnaires. Women were inquired for history of Jaundice and miscarriage. Body mass index (BMI) was calculated by measuring weight and height. Five mls of blood were collected in plain tubes, allowed to clot and centrifugated at room temperature. Then sera were stored at $-20^{\circ} \mathrm{C}$ till transported to Khartoum in dry ice for analyses. Enzyme-linked immunosorbent assay (ELISA) was used for CMV and rubella (IgG and IgM) using commercial diagnostic kits (DRG Instruments GmbH. Germany). Quantitative analysis for CMV and rubella (IgG and IgM) were performed, and the assay result interpreted as $\mathrm{IU} / \mathrm{mL}$. The manufacturer's instructions were followed for the cutoff points, which was $<9 \mathrm{IU} / \mathrm{mL}$ for CMV IgG and IgM. Results $<10$ and $(<68 \mathrm{IU} / \mathrm{mL}$ was considered negative for rubella IgG and IGM, respectively.

\section{Statistics}

Data were entered in the computer using SPSS for windows version 16.0 and double checked before analysis. Means and proportions of the socio-demographic and obstetrical characteristics were calculated for CMV and rubella seropostive groups. Univariate and multivariate analysis were used for CMV and rubella IgG seropostive groups as dependent variable and socio-demographic and obstetrics variables as independent variables. $P$ value $<0.05$ was considered significant.

\section{Result}

Socio-demographic and clinical characteristics

A total of 231 pregnant women were enrolled to the study. The mean (SD) of age, parity and gestational age were 25.7 (5.9) years, 2.5 (2.1), 25.5(9.6) weeks, respectively. More than third (39.4\%) of these women were illiterate. Forty-five (19.5\%) women has history of miscarriage and $60(26 \%)$ had past history of jaundice, table 1.

\section{CMV and rubella seroprevalence}

Out of these 231 pregnant women, 167 (72.2\%) and 6 (2.5\%) had seropostive CMV IgG and IgM, respectively. A total 151 (65.3\%) and 8 (3.4\%) women had seropostive rubella IgG and IgM, respectively. For both CMV and rubella, those women with IgM positive had IgG positive too. One hundred-eight (46.75\%) women had IgG positive for both CMV and rubella.

\section{Risk factors for CMV and rubella virus}

Univariate and multivariate analysis showed that both illiteracy $(\mathrm{OR}=3.0, \mathrm{CI}=1.4-6.5 ; P=0.004)$ high parity [ $>5$ deliveries] $(\mathrm{OR}=14.7, \mathrm{CI}=1.7-123.6 ; P=0.01)$ were significant risk factors for CMV infection. Age was

Table 1 Obstetrical, socio-demographical and clinical characteristic of the pregnant women in El-Rahad Hospital Western Sudan

\begin{tabular}{|c|c|c|c|}
\hline Variables & Total $(N=231)$ & Cytomegalovirus seropostive $(N=167)$ & Rubella seropostive $(N=151)$ \\
\hline Age (years) & $25.7(5.9)$ & $26.5(5.94)$ & $25.6(5.8)$ \\
\hline Haemoglobin (g/dl) & $11.1(1.6)$ & $11.09(1.6)$ & $11.1(1.6)$ \\
\hline Parity & $2.5(2.1)$ & $3.09(2.1)$ & $2.5(2.1)$ \\
\hline Gestational age (weeks) & $25.5(9.6)$ & $26.13(9.4)$ & $26.24(9.3)$ \\
\hline Body mass index & $24(23)$ & 24.65 & $23(4.8)$ \\
\hline \multicolumn{4}{|l|}{ Education level } \\
\hline Illiterate & $91(39.4)$ & $78(46.7)$ & $65(43)$ \\
\hline Primary & $100(43.3)$ & $70(41.9)$ & $67(44.4)$ \\
\hline Secondary & $31(13.4)$ & $17(10.2)$ & $14(9.3)$ \\
\hline University & $9(3.9)$ & $2(1.2)$ & $5(3.3)$ \\
\hline \multicolumn{4}{|l|}{ Occupation } \\
\hline House wife & $104(45.2)$ & $72(43.1)$ & $69(45.7)$ \\
\hline Farmer & $114(49.4)$ & $90(53.9)$ & $76(50.3)$ \\
\hline Employee & $12(5.2)$ & $5(3)$ & $6(4)$ \\
\hline \multicolumn{4}{|l|}{ History of Miscarriage } \\
\hline Yes & $45(19.5)$ & $38(22.8)$ & $31(20.5)$ \\
\hline No & $179(77.5)$ & $126(75.4)$ & $117(77.5)$ \\
\hline \multicolumn{4}{|l|}{ History of Jaundice } \\
\hline Yes & $60(26)$ & $42(25.1)$ & $40(26.5)$ \\
\hline No & $171(74)$ & $125(74.9)$ & $111(73.5)$ \\
\hline
\end{tabular}

Data are expressed as Mean (SD) or number (percentage). 
significantly associated with CMV infection in univariate analyses. Gestational age, history of miscarriage, past history of jaundice, hemoglobin level and body mass index were not significantly associated with CMV infection, table 2. While illiteracy was significantly associated with rubella infection in univariate analyses, none of the investigated socio-demographic obstetrical factors were associated with rubella in multivariate analyses, table 3.

\section{Discussion}

To our knowledge this the first published data in Sudan concerning epidemiology of CMV and rubella among pregnant women. In the current study, the prevalence of CMV IgG was $72.2 \%$. The prevalence of CMV IgG among pregnant women was reported to be higher in other African countries e.g. $97.2 \%$ in Benin [13], 96\% in Egypt [4], and $87 \%$ in Gambia [14]. However, much higher prevalence of CMV was reported in South East Asia [15], while European countries show low prevalence [16]. The low prevalence of CMV in this setting could be explained; firstly by the difference of HIV (which is important co-infection with CMV) prevalence in these settings [17-21]. We have recently observed a low HIV prevalence among pregnant Sudanese women [18]. Secondly, the different socio-demographic, various cultures and behaviors among these settings might have influence and determine epidemiology of CMV e.g. practice of breast feeding, child care and sexual activity [22-24].

Rubella prevalence in this study was $65.3 \%$, hence $34.7 \%$ of the pregnant women are at risk for rubella infection and their unborn babies are vulnerable to congenital rubella syndrome. However, this prevalence is in concert with those reported from Nigeria 68.5\% [25]. Although, there is a high prevalence of CMV all over the world, there is no available vaccine for CMV up to

Table 2 Factors associated with cytomegalovirus (CMV) infection in pregnancy in El-Rahad hospital, Western Sudan, using Univariate and multivariate analysis.

\begin{tabular}{|c|c|c|c|c|c|c|}
\hline \multirow[t]{2}{*}{ Variables } & \multicolumn{3}{|c|}{ Univariate analysis } & \multicolumn{3}{|c|}{ Multivariate analysis } \\
\hline & $\underline{\mathrm{OR}}$ & $\underline{95 \% \mathrm{Cl}}$ & $\underset{\text { value }}{P}$ & $\underline{\mathrm{OR}}$ & $\underline{95 \% \mathrm{Cl}}$ & $\stackrel{P}{\text { value }}$ \\
\hline Age & 1.1 & $1.0-1.1$ & $<0.001$ & 1.0 & $0.9-1.0$ & 0.6 \\
\hline Illiteracy & 3.4 & $1.7-6.7$ & $<0.001$ & 3.0 & $1.4-6.5$ & 0.004 \\
\hline Gestational age & 1.0 & $0.9-1.0$ & 0.1 & 1.0 & $0.9-1.0$ & 0.3 \\
\hline High parity & 22.5 & $\begin{array}{l}3.0- \\
167.3\end{array}$ & 0.002 & 14.7 & $\begin{array}{c}1.7- \\
123.6\end{array}$ & 0.01 \\
\hline $\begin{array}{l}\text { History of } \\
\text { miscarriage }\end{array}$ & 2.2 & $0.9-5.4$ & 0.06 & 1.5 & $0.5-4.4$ & 0.3 \\
\hline History of jaundice & 0.8 & $0.4-1.6$ & 0.6 & 0.5 & $0.2-1.1$ & 0.1 \\
\hline Haemoglobin & 0.9 & $0.7-1.0$ & 0.2 & 0.8 & $0.6-1.0$ & 0.2 \\
\hline Body mass index & 1.0 & $0.9-1.0$ & 0.6 & 1.0 & $0.9-1.0$ & 0.4 \\
\hline
\end{tabular}

Abbreviations: OR, Odds Ratio; $\mathrm{Cl}$, confidence interval
Table 3 Factors associated with Rubella virus infection in pregnancy in El-Rahad hospital Western Sudan, using Univariate and multivariate analysis.

\begin{tabular}{|c|c|c|c|c|c|c|}
\hline \multirow[t]{2}{*}{ Variables } & \multicolumn{3}{|c|}{ Univariate analysis } & \multicolumn{3}{|c|}{ Multivariate analysis } \\
\hline & OR & $95 \% \mathrm{Cl}$ & $P$ value & OR & $95 \% \mathrm{Cl}$ & $P$ value \\
\hline Age & 0.9 & $0.9-1.0$ & 0.7 & 1.0 & $0.9-1.1$ & 0.4 \\
\hline Educational level & 0.6 & $0.4-0.9$ & 0.02 & 0.6 & $0.4-1.0$ & 0.08 \\
\hline Gestational age & 1.0 & $0.9-1.0$ & 0.1 & 1.0 & $0.9-1.0$ & 0.4 \\
\hline Parity & 1.0 & $0.8-1.1$ & 0.9 & 0.9 & $0.7-1.1$ & 0.5 \\
\hline History of miscarriage & 1.1 & $0.5-2.3$ & 0.6 & 1.2 & $0.5-2.8$ & 0.5 \\
\hline History of jaundice & 1.0 & $0.5-2.0$ & 0.8 & 1.2 & $0.6-2.5$ & 0.4 \\
\hline Haemoglobin & 0.9 & $0.7-1.1$ & 0.4 & 0.9 & $0.7-1.0$ & 0.2 \\
\hline Body mass index & 0.9 & $0.9-1.0$ & 0.3 & 0.9 & $0.9-1.0$ & 0.5 \\
\hline
\end{tabular}

Abbreviations: OR, Odds Ratio; $\mathrm{Cl}$, confidence interval

the moment. On the other hand, rubella vaccine - is not yet recommended in Sudan-has been licensed since 1969 [26].

In the current study illiterate women and women with high parity were at higher risk for CMV infection. High parity and illiteracy were observed before as risk factors for increased susceptibility to acquisition CMV infection, perhaps through the direct contact with contagious secretions from their own children and poor hygiene practiced by these women [27-30]. Likewise, low socioeconomic status has been found as a strong risk factor for acquisition CMV infection [28]. Nevertheless in Sudan it is difficult to investigate the socio-economic status of these pregnant women because the culture is based on generous hospitality attitude toward guest and family members who usually lives in extended families.

In the current study age was not significantly associated with CMV or rubella infections. There is a lot of debate concerning maternal age and CMV infection; while many investigators observed that, elder women were at higher risk of CMV infection [28], others reported the reverse [31]. However, Bukbuk et al., documented that, increasing maternal age was significantly associated with rubella infection among Nigerian women [32].

The current study has many limitations; one of these we did not use Polymerase Chain Reaction (PCR) of the viral DNA isolation. The other limitation is the lack of follow-up for these women in order to document seroconveration and to detect fetal infections.

\section{Conclusion}

This study show the prevalence of $72.2 \%$ and $65.3 \%$ of CMV and rubella infections among pregnant women in western of Sudan respectively, illiteracy and high parity are the risk factors for CMV infection. Rubella vaccine is recommended for childbearing age women. More research is needed. 


\section{Ethics}

This study was approved by Sudan Medical specialization Ethics Review Board, Sudan.

\section{Acknowledgements}

The authors are very grateful to all the patients for their co-operation. The study was funded by Sheikan insurance and Sudanese Sugar companies, Khartoum, Sudan.

\section{Author details}

${ }^{1}$ Department of Biochemistry, Faculty of Medicine, Al-Neelain University, Khartoum, Sudan. ${ }^{2}$ Faculty of Medicine, University of Khartoum, Khartoum, Sudan.

\section{Authors' contributions}

$\mathrm{HZH}$ and IEA carried out the study and participated in the statistical analysis and procedures. NMM carried out the practical part of the study. IA coordinated and participated in the design of the study, statistical analysis and the drafting of the manuscript. All the authors read and approved the final version.

\section{Competing interests}

The authors declare that they have no competing interests.

Received: 8 December 2010 Accepted: 11 May 2011

Published: 11 May 2011

\section{References}

1. CA Alford, S Stagno, RF Pass, WJ Britt, Congenital and perinatal cytomegalovirus infections. Rev Infect Dis. 12(7):745-753 (1990). doi:10.1093/clinids/12.Supplement_7.S745

2. M Tabatabaee, D Tayyebi, Seroepidemiologic study of human cytomegalovirus in pregnant women in Valiasr Hospital of Kazeroon, Fars, Iran. J Matern Fetal Neonatal Med. 22(6):517-21 (2009). doi:10.1080/ 14767050902801678

3. MJ Cannon, DS Schmid, TB Hyde, Review of cytomegalovirus seroprevalence and demographic characteristics associated with infection. Rev Med Virol. 20(4):202-13 (2010). doi:10.1002/rmv.655

4. A el-Nawawy, AT Soliman, O el Azzouni, el-S Amer, MA Karim, S Demian, M el Sayed, Maternal and neonatal prevalence of toxoplasma and cytomegalovirus (CMV) antibodies and hepatitis-B antigens in an Egyptian rural area. J Trop Pediatr. 42(3):154-7 (1996). doi:10.1093/tropej/42.3.154

5. KB Fowler, RF Pass, Risk factors for congenital cytomegalovirus infection in the offspring of young women: exposure to young children and recent onset of sexual activity. Pediatrics. 118(2):286-92 (2006). doi:10.1542/ peds.2005-1142

6. S Stagno, Cytomegalovirus. in Infectious diseases of the fetus and newborn infant, ed. by Remington JS, Klein JO (Philadelphia, W.B. Saunders Company, 2001), pp. 389-424

7. Epidemiology and prevention of vaccine-preventable disease. Thepink book., 8 http://www.cdc.gov/vaccines/pubs/pinkbook/downloads/prinvac. pdf (2004)

8. P Ojala, T Vesikari, O Elo, Rubella during pregnancy as a cause of congenital hearing loss. Am J Epidemiol. 98(5):395-401 (1973)

9. Centers for Disease Control and Prevention (CDC), Progress toward contro of rubella and prevention of congenital rubella syndrome - worldwide, 2009. MMWR Morb Mortal Wkly Rep. 59(40):1307-10 (2010)

10. J Barreto, I Sacramento, SE Robertson, J Langa, E de Gourville, L Wolfson, BD Schoub, Antenatal rubella serosurvey in Maputo, Mozambique. Trop Med Int Health. 11(4):559-64 (2006). doi:10.1111/j.1365-3156.2006.01577.x

11. SE Robertson, DA Featherstone, M Gacic-Dobo, BS Hersh, Rubella and congenital rubella syndrome: global update. Rev Panam Salud Publica. 14(5):306-15 (2003)

12. A Elnahas, AS Gerais, MI Elbashir, ES Eldien, I Adam, Toxoplasmosis in pregnant Sudanese women. Saudi Med J. 24(8):868-70 (2003)

13. MH Rodier, J Berthonneau, A Bourgoin, G Giraudeau, G Agius, C Burucoa, A Hekpazo, JL Jacquemin, Seroprevalences of Toxoplasma, malaria, rubella, cytomegalovirus, HIV and treponemal infections among pregnant women in Cotonou, Republic of Benin. Acta Trop. 59(4):271-7 (1995). doi:10.1016/ 0001-706X(95)00087-U

14. C Bello, H Whittle, Cytomegalovirus infection in Gambian mothers and their babies. J Clin Pathol. 44(5):366-9 (1991). doi:10.1136/jcp.44.5.366

15. T Taechowisan, R Sutthent, S Louisirirotchanakul, P Puthavathana, C Wasi, Immune status in congenital infections by TORCH agents in pregnant Thais. Asian Pac J Allergy Immunol. 15(2):93-7 (1997)

16. O Picone, C Vauloup-Fellous, AG Cordier, I Parent Du Châtelet, MV Senat, R Frydman, L Grangeot-Keros, A 2-year study on cytomegalovirus infection during pregnancy in a French hospital. BJOG. 116(6):818-23 (2009). doi:10.1111/j.1471-0528.2009.02139.x

17. S Mujtaba, S Varma, S Sehgal, Cytomegalovirus co-infection in patients with HIV/AIDS in north India. Indian J Med Res. 117, 99-103 (2003)

18. DE Gassmelseed, AM Nasr, SM Homeida, MA Elsheikh, I Adam, Prevalence of HIV infection among pregnant women of the central Sudan. J Med Virol. 78(10):1269-70 (2006). doi:10.1002/jmv.20694

19. RH Gray, X Li, G Kigozi, D Serwadda, H Brahmbhatt, F Wabwire-Mangen, F Nalugoda, M Kiddugavu, N Sewankambo, TC Quinn, SJ Reynolds, MJ Wawer, Increased risk of incident HIVduring pregnancy in Rakai, Uganda: A prospective study. Lancet. 366(9492):1182-8 (2005). doi:10.1016/S0140-6736 (05)67481-8

20. M Mseleku, TH Smith, F Guidozzi, HIV seropositive in pregnant South African women who initially refuse routine antenatal HIVscreening. Brit J Obstet. 112(3):370-1 (2005). doi:10.1111/j.1471-0528.2004.00424.x

21. M Fabiani, B Nattabi, AA Opio, J Musinguzi, B Biryahwaho, EO Ayella, M Ogwang, S Declich, A high prevalence of HIV-1 infection among pregnant women living in a rural district of north Uganda severely affected by civil strife. Trans Roy Soc Trop Med Hyg. 100(6):586-593 (2006). doi:10.1016/j. trstmh.2005.09.002

22. CS Peckham, C Johnson, A Ades, K Pearl, KS Chin, Early acquisition of cytomegalovirus infection. Arch Dis Child. 62(8):780-5 (1987). doi:10.1136/ adc.62.8.780

23. SP Adler, Cytomegalovirus transmission among children in day care, their mothers and caretakers. Pediatr Infect Dis J. 7(4):279-85 (1988). doi:10.1097/ 00006454-198804000-00009

24. HH Handsfield, SH Chandler, VA Caine., et al, Cytomegalovirus infection in sex partners: evidence for sexual transmission. Jnfect Dis. 151(2):344-8 (1985). doi:10.1093/infdis/151.2.344

25. AE Bamgboye, KA Afolabi, FI Esumeh, IB Enweani, Prevalence of rubella antibody in pregnant women in Ibadan, Nigeria. West Afr J Med. 23(3):245-8 (2004)

26. HL Ooi, SM Cheong, S Yogeswery, I Norizah, H Zuridah, V Kumarasamy, KB Chua, Congenital rubella syndrome with positive serology and virus isolation. Med J Malaysia. 61(2):248-50 (2006)

27. A Kramer, I Schwebke, G Kampf, How long do nosocomial pathogens persist on inanimate surfaces? A systematic review. BMC Infect Dis. 6, 130 (2006). doi:10.1186/1471-2334-6-130

28. SL Bate, SC Dollard, MJ Cannon, Cytomegalovirus seroprevalence in the United States: the national health and nutrition examination surveys, 19882004. Clin Infect Dis. 50(11):1439-47 (2010). doi:10.1086/652438

29. BF Walmus, MD Yow, JW Lester, L Leeds, PK Thompson, RM Woodward, Factors predictive of cytomegalovirus immune status in pregnant women. J Infect Dis. 157(1):172-7 (1988). doi:10.1093/infdis/157.1.172

30. JB Dowd, MN Haan, L Blythe, K Moore, AE Aiello, Socioeconomic gradients in immune response to latent infection. Am J Epidemiol. 167(1):112-20 (2008)

31. CB Correa, V Kourí, D Verdasquera, PA Martínez, A Alvarez, Y Alemán, L Pérez, J Viera, R González, E Pérez, I Moro, MA Navarro, P Melin, HCMV seroprevalence and associated risk factors in pregnant women, Havana City, 2007 to 2008. Prenat Diagn. 30(9):888 (2010). doi:10.1002/pd.2587

32. DN Bukbuk, AU el Nafaty, JY Obed, Prevalence of rubella-specific IgG antibody in non-immunized pregnant women in Maiduguri, north eastern Nigeria. Cent Eur J Public Health. 10(1-2):21-3 (2002)

doi:10.1186/1743-422X-8-217

Cite this article as: Hamdan et al: Seroprevalence of cytomegalovirus and rubella among pregnant women in western Sudan. Virology Journal $20118: 217$ 